\title{
Design and implementation of variable and constant load for induction motor
}

Salam Waley Shneen ${ }^{1}$, Hashmia Sh.Dakheel ${ }^{2}$, Zainab B.Abdulla ${ }^{3}$

${ }^{1}$ Energy and Renewable Energies Technology Center, University of Technology, Iraq

${ }^{2,3}$ Department of Electromechanical, University of Technology, Iraq

\begin{tabular}{l}
\hline Article Info \\
\hline Article history: \\
Received Jul 19, 2019 \\
Revised Dec 2, 2019 \\
Accepted Feb 4, 2020 \\
\hline
\end{tabular}

Keywords:

FLC

IM

PI

Transfer function

\begin{abstract}
To design and implementation of variable and constant with no load for induction motor (IM) that is the goal in this work. This paper was including three parts, first the simulation model with no load for IM, Second the simulation model with constant load for IM, Third the simulation model with variable load for IM. In addition, this work includes comparative between two different controllers (PI and fuzzy logic control (FLC). The simulation results clearly the implementation of variable and constant with no load for IM. The simulation response of the system achieves better results when choosing to use type fuzzy-PI controller technique comparison with conventional PI controller and improve the performance of the system at different operation conditions.
\end{abstract}

This is an open access article under the $\underline{C C B Y-S A}$ license.

\section{Corresponding Author:}

Salam Waley Shneen,

Energy and Renewable Energies Technology Center,

University of Technology,

52 Industry street, Baghdad, Iraq.

Email: salam_waley73@yahoo.com

\section{INTRODUCTION}

The 3-phase IM is important of electrical machines that widely used in different industrial applications [1]. They perform their characteristic for decades and adapt themselves at different operate conditions [2], such as oil refineries, electric power stations, and factories because their simple in design, high efficiency, good self-starting, good power factor, low manufacturing costs relatively, and small value of inertia [3]. The disadvantages of IM have represented in non-linear multivariable in addition to complex of mathematical model, so IM inherently unable to operate at different range of speed, therefore to solve these problems is used multi types of controllers such as PI controllers. Very comprehensive remarks era that gives a very efficient method to several manipulate problems inside the real world. These controllers are simplicity, reliability. Robust of the systems and tuned properly therefore they becomes important in industrial applications.

However, PI controller can't offer the good control overall performance in running condition [4]. The authors of [5-7] are present hybrid control system by using FLC and conventional controllers by using mathematical of IM and these studies deals with the structure of model to obtain high-performance tracking of IM. In [8] proposes speed control of IM by using conventional techniques (PI and PID) controllers with vector control technique at full load condition and discuss simulation results with these controllers and without any controller. The study [9] proposes system to control on speed of IM by using feedback close loop system with fuzzy-PID controller. This system has other advantages that combination between 3-phase step-up transformer and 3-phase drive to able control any 3-phase machine on a 1-phase supply, also study [10] refers speed control of IM by using MATLAB Toolbox and Simulink model to developed this model by using FLC which available constant speed at varies loads conditions. Many studies had proposed different approach to resolve the downside of (PI controller). The usage of artificial intelligence techniques (AIT) so one of these techniques are very important for controlling non-linear system without independent on behaviors of internal system such as (FLC) that 
permits designers to address efficaciously difficult closed loop system in order to reduce time as well as costs, supports non-linear system which can be using in motor control fields [11]. PI controller can be tuned the gain by (AIT), (FLC) and online tuned with changing conditions of system [12], the controller gains are the best advantage of these controllers because which allow using the human experience for the generation of the tuning law [13]. This study provides fuzzy-PI controller that FLC adjust parameters of PI and comparative with conventional PI controller at different operation conditions include (no load, constant and variable loads) of IM in order to improve operation of this motor and obtain high performance at real time.

\section{MATHEMATICAL MODEL OF IM:-}

The equivalent circuit of IM for ( $q$ and $d$ winding circuit) which can be used to analysis the model of IM shows in Figure 1, while power circuit of the 3-phase IM shows in Figure $2[14,15]$.

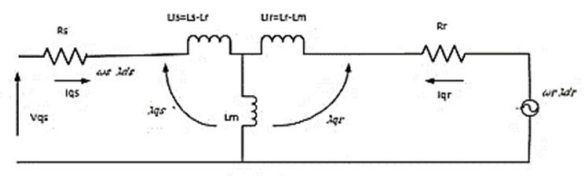

(a) q-circuit

(a)

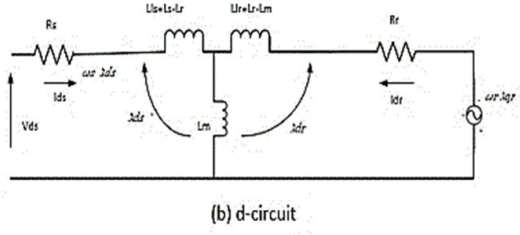

(b)

Figure 1. Equivalent circuit of IM

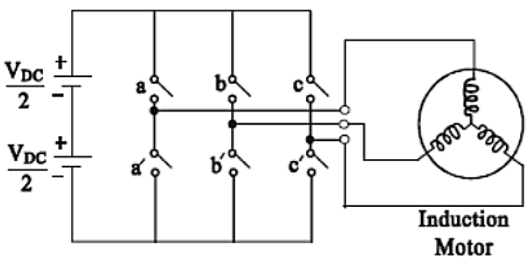

Figure 2. Power circuit of 3-phase IM

Dynamic model of IM can represent by writing deferential equation for electrical and mechanical quantities (voltage and torque) and can shown in mathematical model of IM include the equations below [3].

\section{A-Electrical system equations}

$$
\begin{aligned}
& v_{s}=R_{S} i_{s}+\frac{1}{w_{0}} \frac{d \lambda_{s}}{d t}+w_{k} M_{\frac{n}{2}} \lambda_{s} \\
& v_{s}=R_{r} i_{r}+\frac{1}{w_{0}} \frac{d \lambda_{r}}{d t}+\left(w_{k}-w_{m}\right) M_{\frac{n}{2}} \lambda_{r}
\end{aligned}
$$

Here $\lambda=\left[\frac{\lambda_{d}}{\lambda_{q}}\right], i=\left[\frac{i_{d}}{i_{q}}\right], M_{\frac{n}{2}}=\left[\begin{array}{cc}0 & -1 \\ 1 & 0\end{array}\right]$

\section{B- Flux linkage-current relations} For d-axis:

$$
\begin{aligned}
& \lambda_{s d}=L_{s} i_{s d}+L_{m} i_{r d} \\
& \lambda_{r d}=L_{m} i_{s d}+L_{r} i_{r d}
\end{aligned}
$$

For q axis:

$$
\begin{aligned}
& \lambda_{s q}=L_{s} i_{s q}+L_{m} i_{r q} \\
& \lambda_{r q}=L_{m} i_{s q}+L_{r} i_{r q}
\end{aligned}
$$

Where $L_{s}=L_{m}+L_{s l}, L_{r}=L_{m}+L_{r l}$ 


\section{C- Mechanical system equations:-}

$$
T_{e}=2 H \frac{d w_{m s e c}}{d t}+B_{m} w_{s e}+T_{e}
$$

Where $T_{e}, \lambda_{s} * i_{s}=M_{\frac{n}{2}} \lambda_{s} * i_{s}$

$$
w_{s e}=\frac{2}{p} w_{m}
$$

\section{Induction motor and controller}

This paper proposes operation of IM at different conditions such as (no load, constant and variable loads) without controller and by using each of PI and fuzzy-PI controller to develop performance of IM at different operation conditions, the following steps in this paper present in the flow chart which shows in Figure 3.

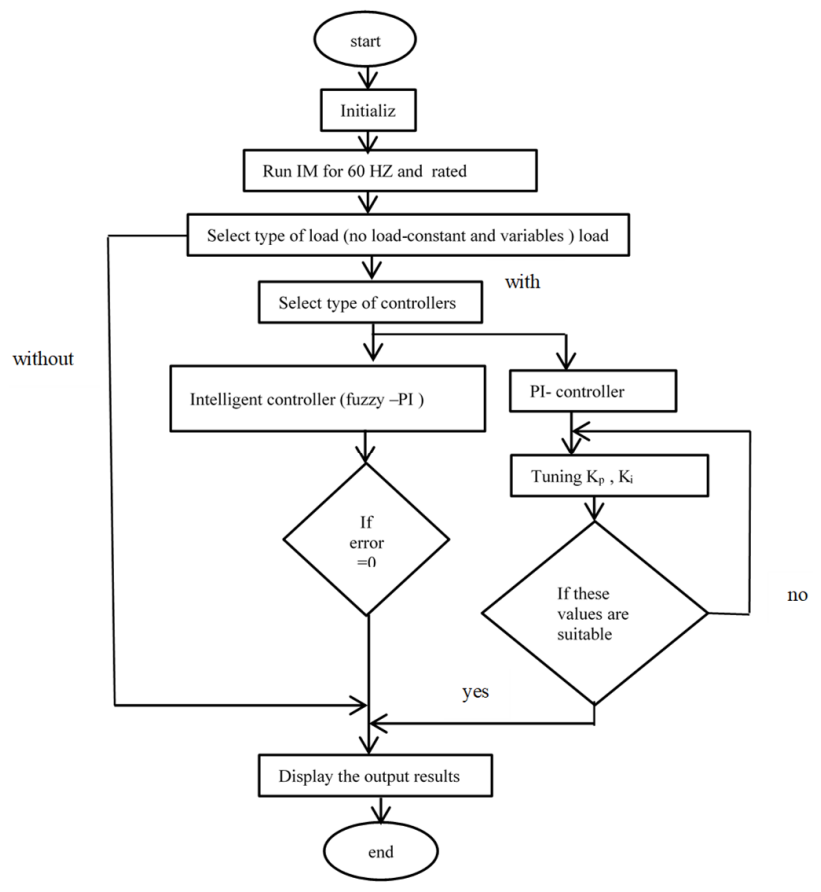

Figure 3. Flow chart for performance of model

\subsection{Simulation of induction motor}

The 3-phase voltages and frequency are inputs of a squirrel cage IM, while the 3-phase currents, torque and rotor speed are outputs of IM model [14]. Simulink model of IM shows in Figure 4.

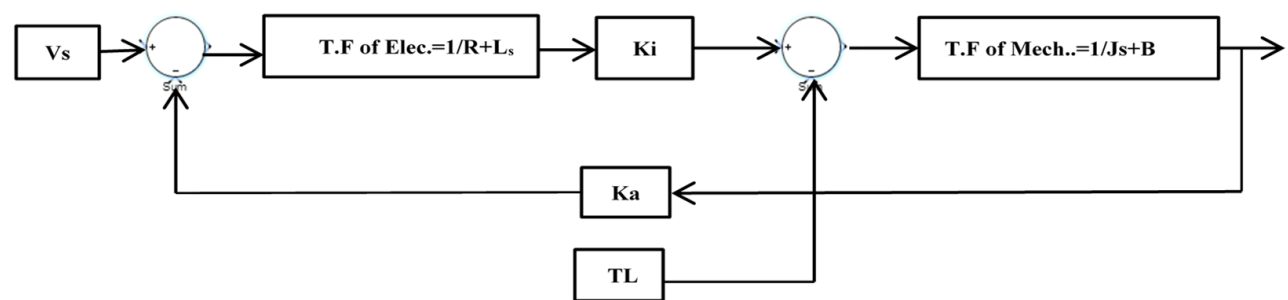

Figure 4. Simulink model of IM 
The parameters of the IM propose in this paper as shown in Table 1.

\begin{tabular}{ll}
\multicolumn{2}{l}{ Table 1. parameters of IM } \\
\hline parameters & values \\
\hline $\mathrm{P}(\mathrm{AV})$ & $3^{*} 746$ \\
$\mathrm{~V}($ line-line $)$ & 220 (r.m.s) \\
$\mathrm{f}(\mathrm{Hz})$ & 60 \\
$\mathrm{R}_{\mathrm{s}}(\Omega)$ & 0.435 \\
$\mathrm{~L}_{\mathrm{s}}(\mathrm{H})$ & $2^{*} 2 \mathrm{e}-3$ \\
$\mathrm{R}_{\mathrm{r}}(\Omega)$ & 0.816 \\
$\mathrm{~L}_{\mathrm{r}}(\mathrm{H})$ & $2 \mathrm{e}-3$ \\
$\mathrm{~L}_{\mathrm{m}}(\mathrm{H})$ & $69.31 \mathrm{e}-3$ \\
$\mathrm{~J}\left(\mathrm{~kg} \cdot \mathrm{m}^{\wedge} 2\right)$ & 0.089 \\
$\mathrm{~F}_{\mathrm{c}}$ & 0 \\
Pole pair & 2 \\
\hline
\end{tabular}

Where:

$\mathrm{P}=$ power, $\mathrm{V}=$ Voltage, $\mathrm{f}=$ frequency, $\mathrm{R}_{\mathrm{s}}=$ stator resistance, $\mathrm{L}_{\mathrm{s}}=$ stator inductance, $\mathrm{R}_{\mathrm{r}}=$ rotor resistance, $\mathrm{L}_{\mathrm{r}}=$ rotor inductance, $\mathrm{L}_{\mathrm{m}}=$ mutual inductance, $\mathrm{J}=$ inertia, $\mathrm{F}_{\mathrm{c}}=$ friction factor.

\subsection{PI controller}

PI controller can propose high performance only when the controller system operates at operating point, so the PI controller does not frequently properly tune at operating condition changes and variations of parameters, in order to develop automatic tuning of PI controller parameters [13]. PI controller drives plant to control weighted summation of error and integration of values. The conventional or linear PI controller has described in 10.

$$
Y(t)=e(t) K_{P}+K_{i} \int_{0}^{t} e(t) d t
$$

Where $\mathrm{Kp}$ is the proportional gain and $\mathrm{Ki}$ is integral gain of controller while error signal $\mathrm{e}(\mathrm{t})$ is the difference between the reference $r(t)$ and the process output $\mathrm{c}(\mathrm{t})[8]$.

$$
e(t)=r(t)-c(t)
$$
this controller.

Table 2. indicates effect of parameters for PI on controller system, whereas Figure 5 refers to block diagram of

Table 2. effect of parameters of PI

\begin{tabular}{ccccc}
\hline parameters & $\mathrm{t}_{\text {rise }}$ & $\mathrm{t}_{\text {over shoot }}$ & $\mathrm{t}_{\text {tuning }}$ & $\mathrm{e}_{\text {rror }}$ \\
\hline $\mathrm{k}_{\mathrm{p}}$ & Dec. & Incr. & Small change & Dec. \\
$\mathrm{k}_{\mathrm{i}}$ & Dec. & Incr. & Incr. & eliminate \\
\hline
\end{tabular}

Where:

Dec. $=$ decrese, Incr $=$ increase,

Figure 6 shows PI -controller structure $(\mathrm{kp}, \mathrm{ki})$ are input of PI -controller and $(\mathrm{u})$ is output $[16,17]$.
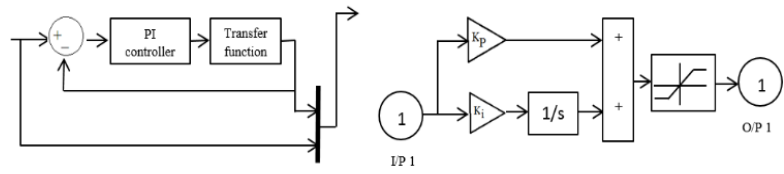

Figure 5. Simulink and block diagram of PI controller

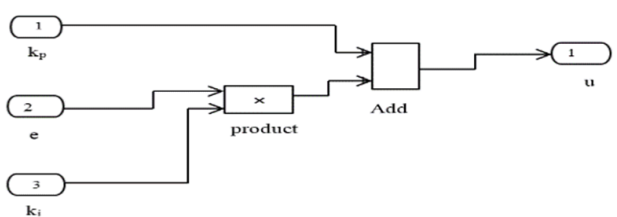

Figure 6. The structure of PI controller

\subsection{Fuzzy-PI controller}

The (FLC) is one of best applications where the fuzzy theory can apply successfully, so it can solve problems in nonlinear control system but the system model is complex to build therefore knowledge of the process is important to obtain the fuzzy rules. (FLC) consists of 3 steps: 1) fuzzification 2) evaluation of control rules 3) defuzzification [18]. (FLC) have the advantages more than the classical control. They are

Design and implementation of variable and constant load for induction motor (Salam Waley Shneen) 
including wide range of operating cases. Cheaper to improve and easier in neural language expressions. Mamdani is type of (FLC) can use in two systems. The first is multiple inputs multiple outputs while the other is multiple input and signal output system. The interest of (FLC) is adopted operators experiment or knowledge of the system in a heuristic way and in design process, the thresholds of fuzzy lingual variables are often selection randomly so an incorrect controller values reach to unstable mode, an opposite consequence, breakdown and separation [19, 20]. Figure 7 refers to block diagram of (FLC) [21].

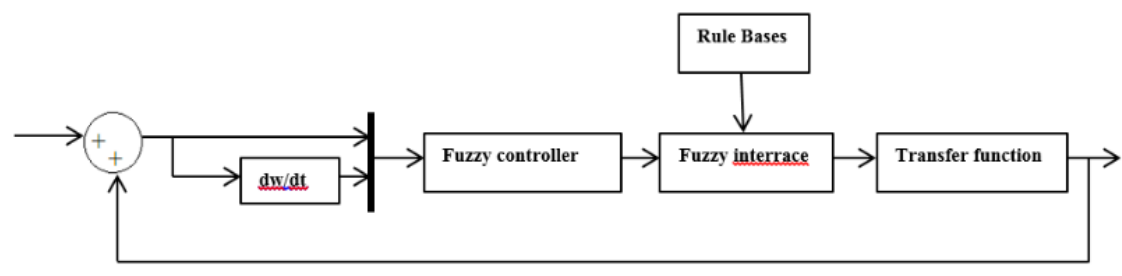

Figure 7. Block diagram of (FLC)

The main goales of (fuzzy-PI) controller are to decrease control planner complication and develop dynamic and static performances of the system. Essentially for systems designing are complex. The parameters are difficult to obtain in this state. The (PI) controller is designed to set parameters $\mathrm{Kp}$ and $\mathrm{Ki}$ orderly to meet suitable required characteristics include rise time, maximum value of overshoot, steady state error and settling time. Therefore, (FLC) control signal according to the integral and proportional actions of the PI-controller [13]. (FLC) has (2) inputs are represented error $\mathrm{e}(\mathrm{k})$ and change of error $\Delta \mathrm{e}(\mathrm{k})$.

$\mathrm{e}(\mathrm{k})=\mathrm{r}(\mathrm{k})-\mathrm{y}(\mathrm{k}), \Delta \mathrm{e}(\mathrm{k})=\mathrm{e}(\mathrm{k})-\mathrm{e}(\mathrm{k}-1)$

where $(\mathrm{r})$ indicated to applied set point input and $(\mathrm{y})$ denote to plant output, $(\mathrm{k})$ indicate present state whereas $\left(\mathrm{k}^{-1}\right)$ is previous case of this system, while output of (FLC) is gradual change in value of $\Delta \mathrm{e}(\mathrm{k})$ [22], Figure 8 inducates to block diagram of ( fuzzy-PI ) controller [23].

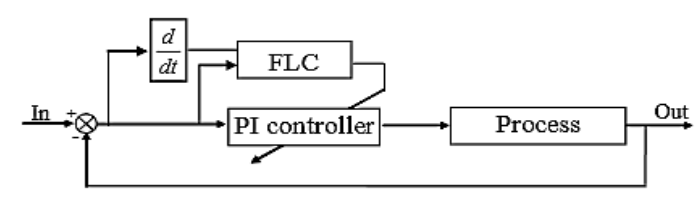

Figure 8. Block diagram of (fuzzy -PI) controller

\section{SIMULINK MODEL AND SIMULATION RESULTS}

\subsection{Simulink model}

Figure 9 Shows simulation model of IM without controller at variable conditions of load (no load, constant and variable load) as follows.

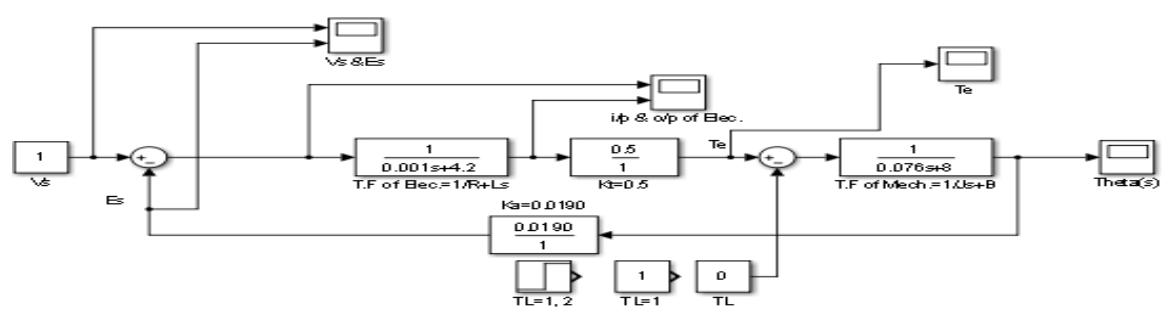

Figure 9. Simulink Model of I.M without Controller 
Simulation Model of I.M with PI Controller at variable loads (no load, constant and variable loads) as shown in Figure 10. In addition, Simulink Model of I.M with PI Controller at variable loads (no load, constant and variable load) as shown in Figure 11.

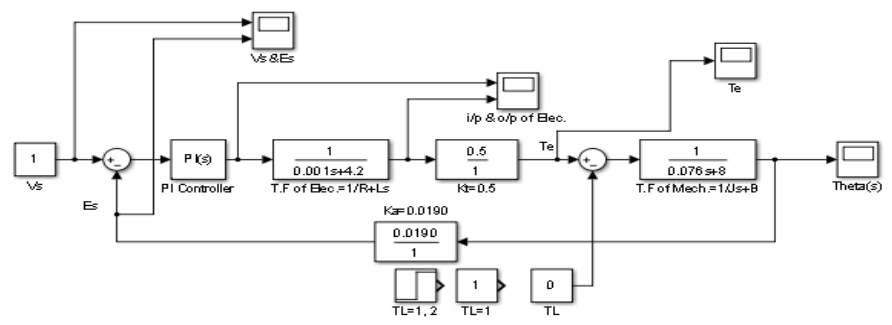

Figure 10. Simulink model of I.M with PI- Controller

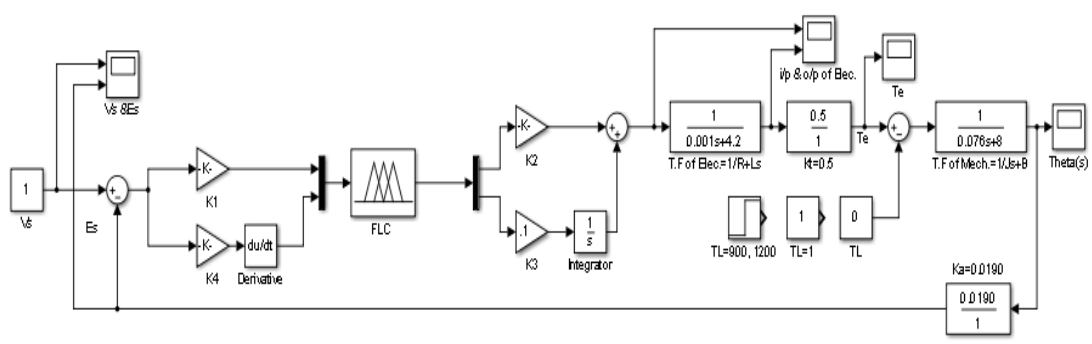

Figure 11. Simulink model of I.M with (fuzzy-PI) Controller

\subsection{Simulation results}

The simulation results include, at no load, at constant load with PI controller and with fuzzy-PI (FLPI) controller.

\subsubsection{The simulation results at no load include:}

The simulation results discuss three different states, the first includes operation of motor without any controller while two other states discuss the performance with two techniques had represented in PI and fuzzy-PI controller.

First, simulation results without control at no load and the simulation response of the system at no load without any controllers can be show in the Figure 12.

Second part includes simulation results with PI controller at no load; Figure 1) shows the simulation response of the system.

Third part discuss the response of the system by using fuzzy-PI (FLPI) controller at no load condition, the simulation results of this part can be shown in Figure 14.

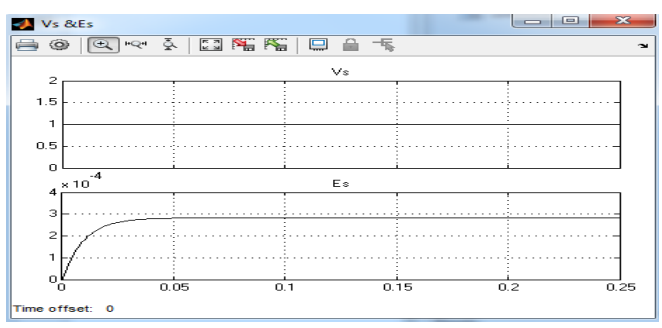

(a)

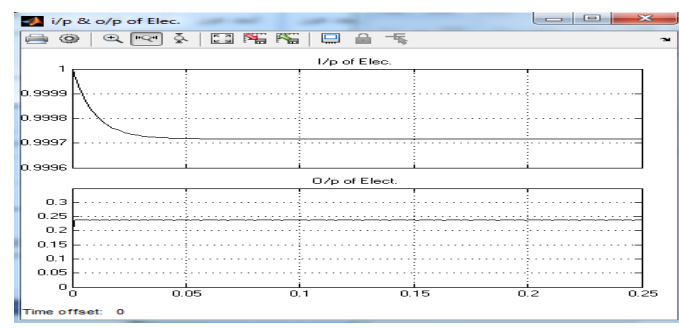

(b) 


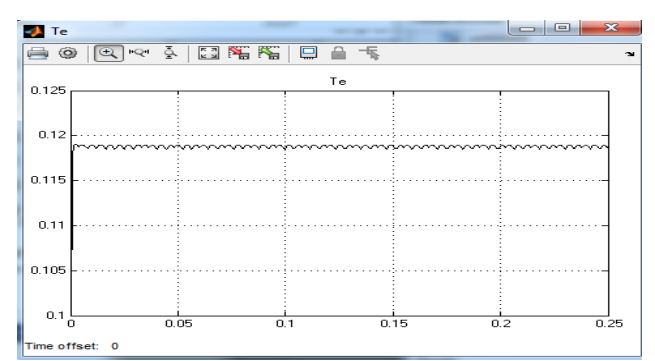

(c)

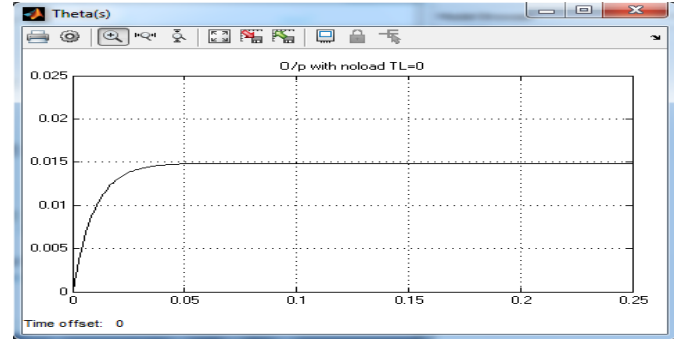

(d)

Figure 12. Simulation response of the system at no load without controller, (a) Simulation response of the Vs \& Es, (b) Simulation response of i/p \& o/p, (c) Simulation response of Te, (d) Simulation response of o/p

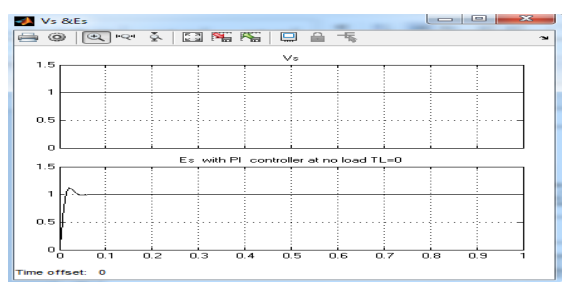

(a)

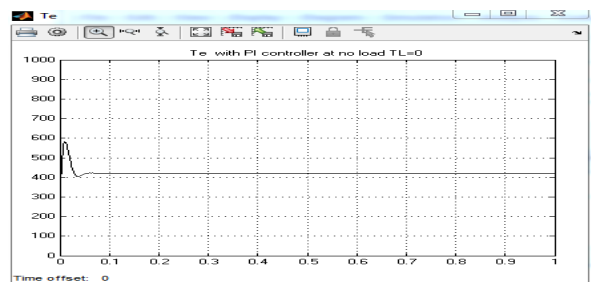

(c)

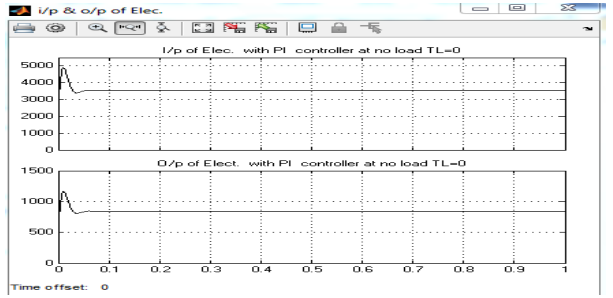

(b)

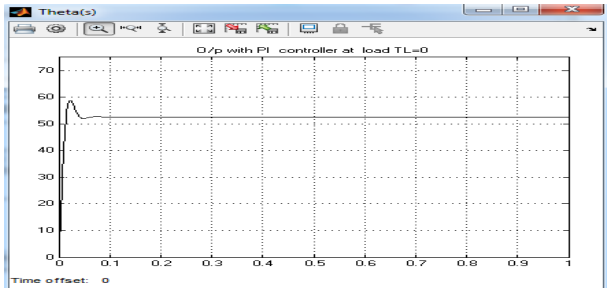

(d)

Figure 13. Simulation response of the system at no load with PI controller, (a) Simulation response of the Vs \& Es, (b) Simulation response ofi/p \& o/p, (c) Simulation response of Te, (d) Simulation response of o/p

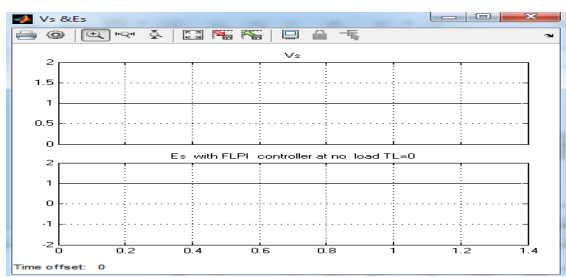

(a)

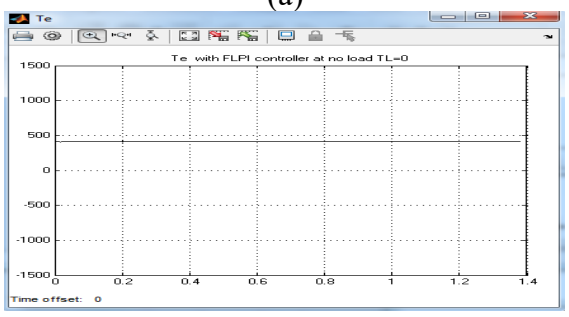

(c)

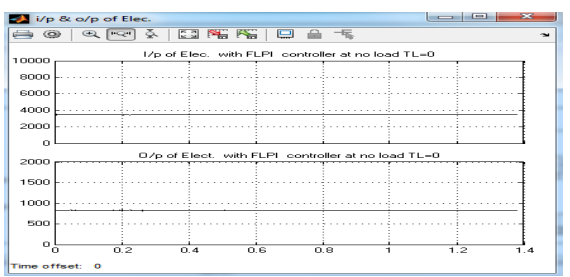

(b)

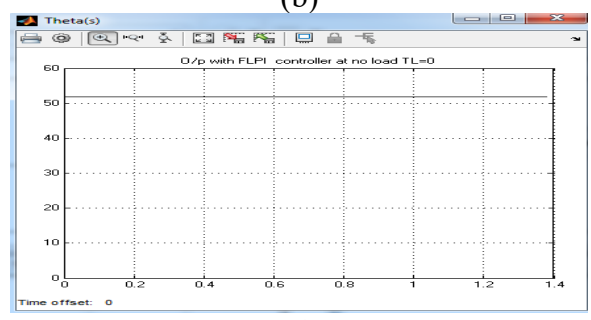

(d)

Figure 14. Simulation response of the system at no load with FLPI controller, (a) Simulation response of the Vs \& Es, (b) Simulation response of i/p \& o/p, (c) Simulation response of Te, (d) Simulation response of o/p 


\subsubsection{The Simulation results at constant load include:}

First, simulation results without control at constant load and the simulation response of the system at no load without any controllers can be show in the Figure 15. Second part includes simulation results with PI controller at constant load; Figure 16 shows the simulation response of the system. Third part discuss the response of the system by using fuzzy-PI (FLPI) controller at constant load condition, the simulation results of this part can be shown in Figure 17.

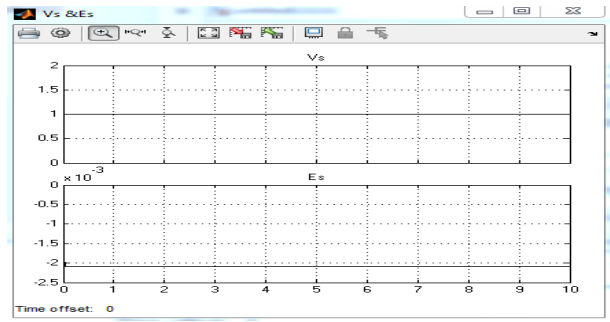

(a)

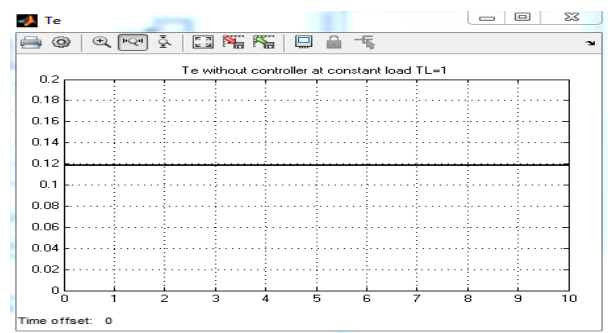

(c)

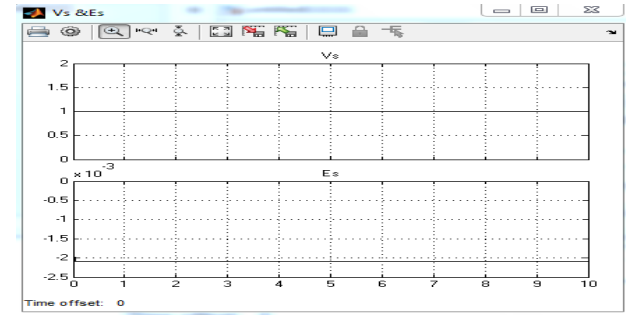

(b)

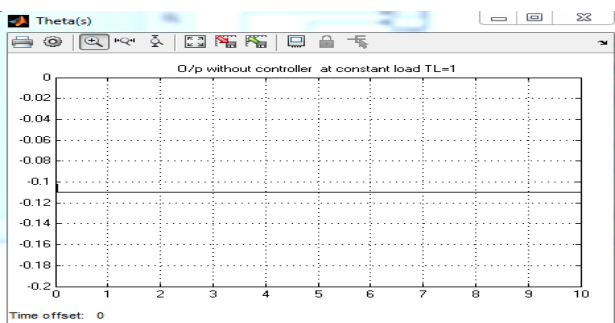

(d)

Figure 15. Simulation response of the system at constant load without controller,

(a) Simulation response of the Vs \& Es, (b) Simulation response of i/p \& o/p, (c) Simulation response of Te, (d) Simulation response of $\mathrm{o} / \mathrm{p}$

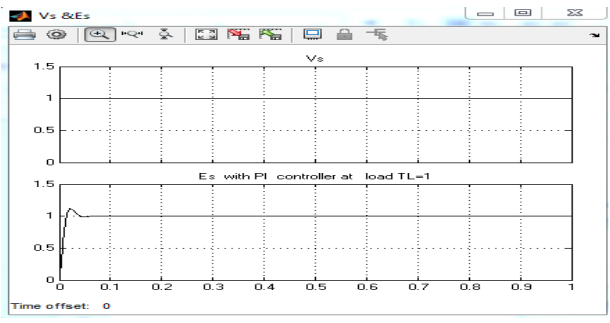

(a)

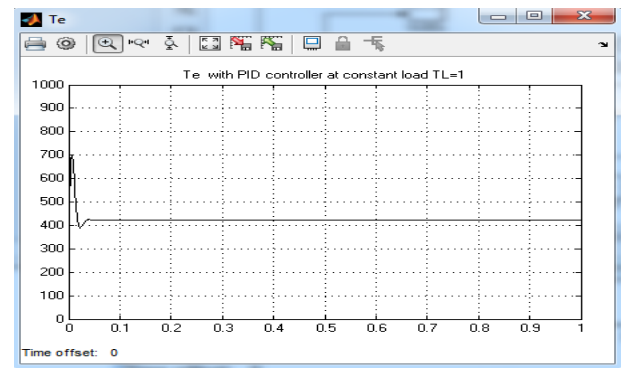

(c)

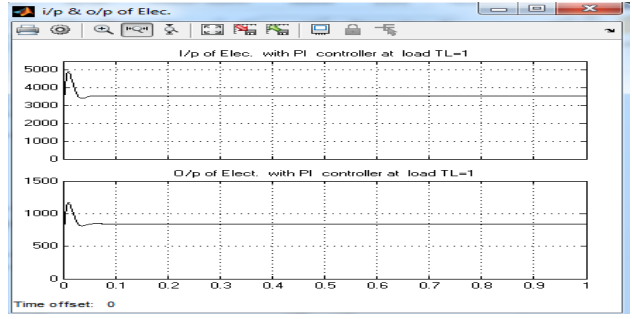

(b)

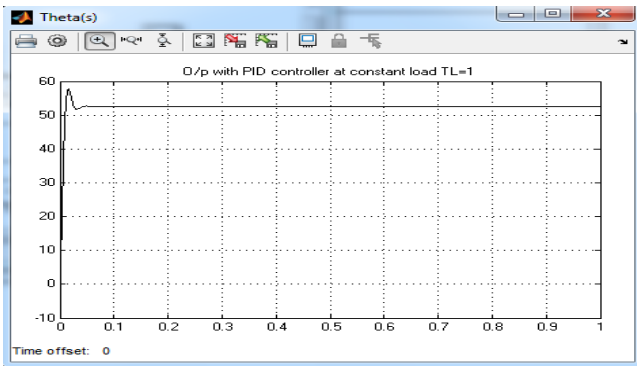

(d)

Figure 16. Simulation response of the system at constant load with PI controller,

(a) Simulation response of the Vs \& Es, (b) Simulation response of i/p \& o/p, (c) Simulation response of Te,

(d) Simulation response of $\mathrm{o} / \mathrm{p}$ 


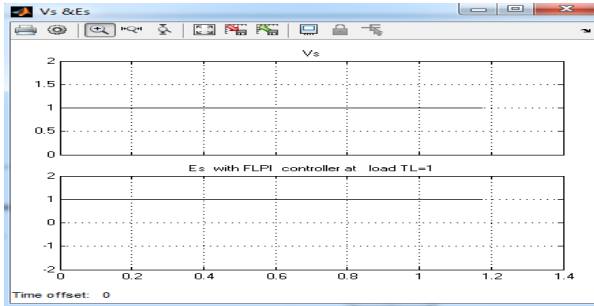

(a)

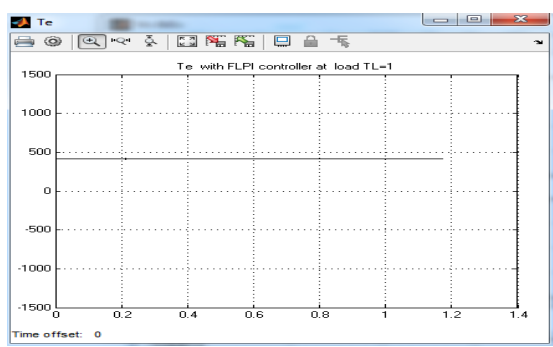

(c)

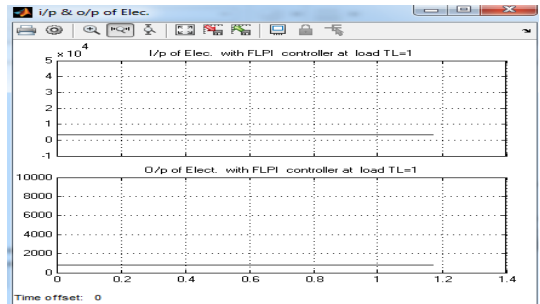

(b)

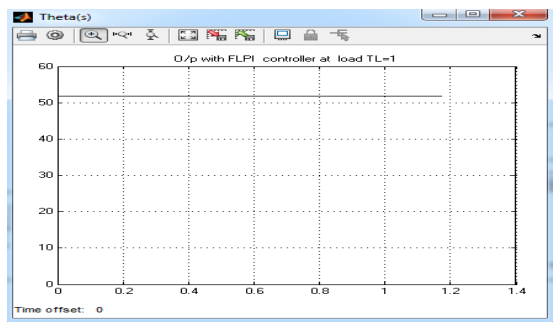

(d)

Figure 17. Simulation response of the system at constant load with FLPI controller, (a) Simulation response of the Vs \& Es, (b) Simulation response of i/p \& o/p, (c) Simulation response of Te, (d) Simulation response of $\mathrm{o} / \mathrm{p}$

\subsubsection{The Simulation results at variable load include:}

First, simulation results without control at variable load and the simulation response of the system at no load without any controllers can be show in the Figure 18. Second part includes simulation results with PI controller at variable load; figure (19) shows the simulation response of the system. Third part discuss the system by using fuzzy-PI (FLPI) controller at variable load condition, the simulation results of this part can be shown in Figure 20.

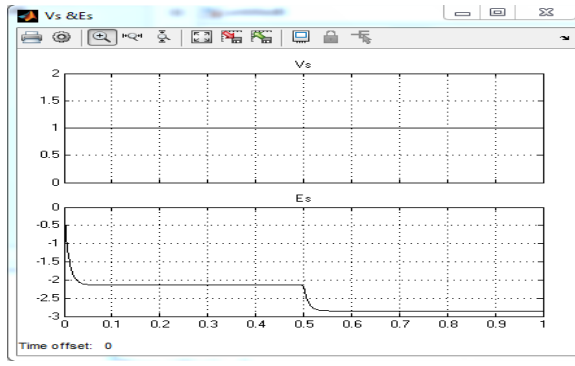

(a)

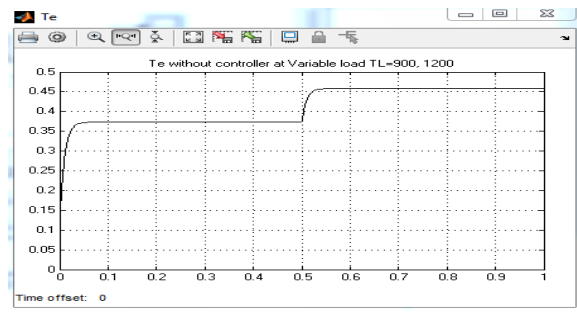

(c)

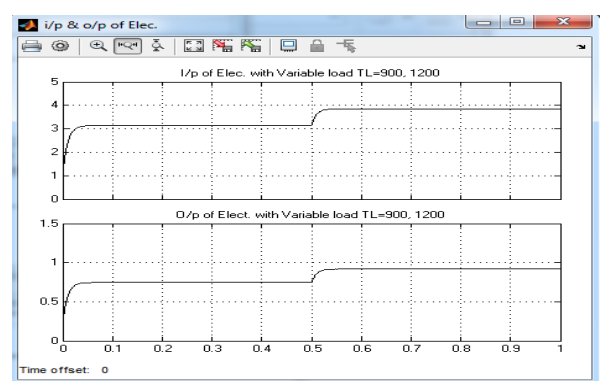

(b)

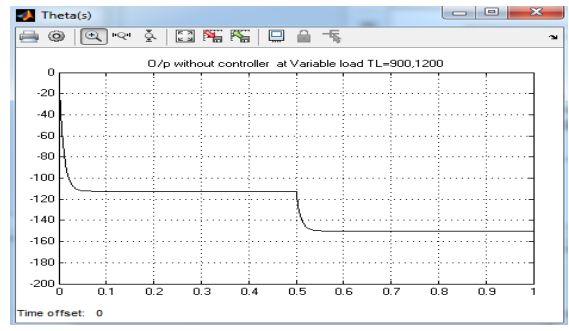

(d)

Figure 18. Simulation response of the system at variable load without controller,

(a) Simulation response of the Vs \& Es, (b) Simulation response of i/p \& o/p, (c) Simulation response of Te, (d) Simulation response of $\mathrm{o} / \mathrm{p}$ 


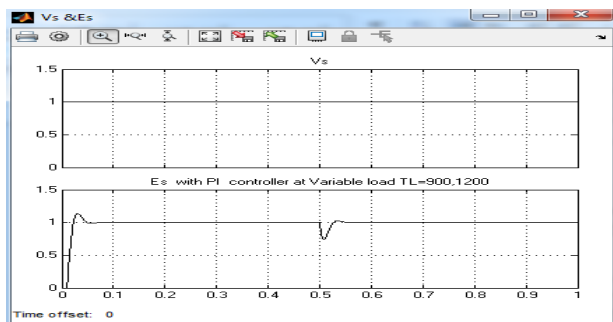

(a)

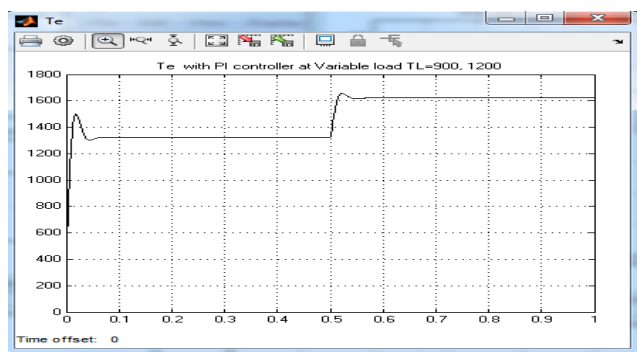

(c)

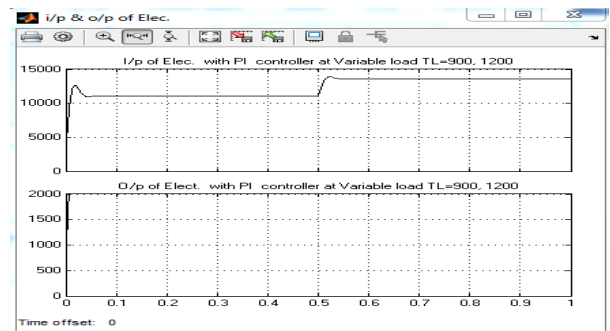

(b)

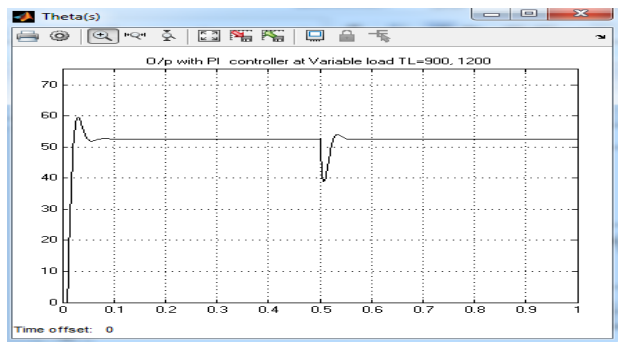

(d)

Figure 19. Simulation response of the system at variable load with PI controller,

(a) Simulation response of the Vs \& Es, (b) Simulation response of i/p \& o/p, (c) Simulation response of Te,

(d) Simulation response of $\mathrm{o} / \mathrm{p}$

This part includes the simulation results of the system by using fuzzy-PI controller Figure 20 shows each of FIS, memberships, rules, surface viewers respectively.

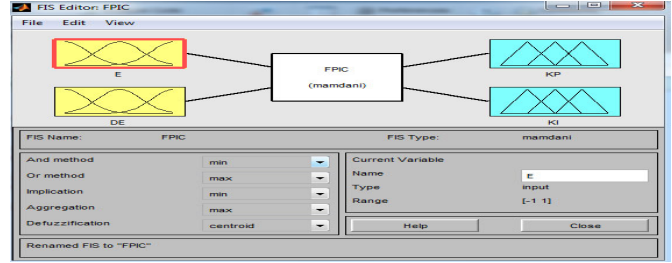

(a)

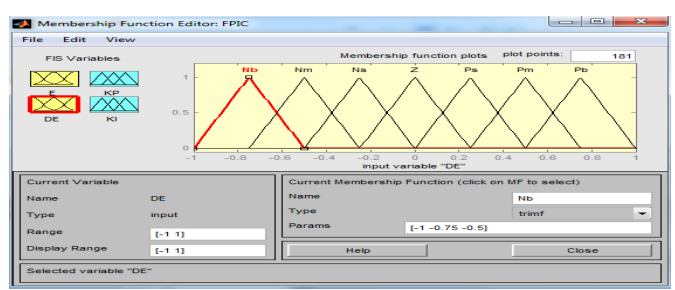

(c)

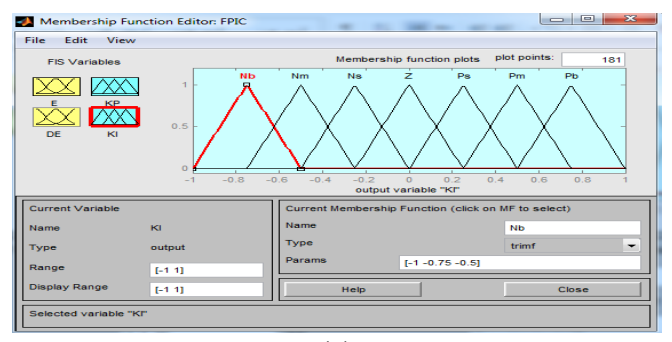

(e)

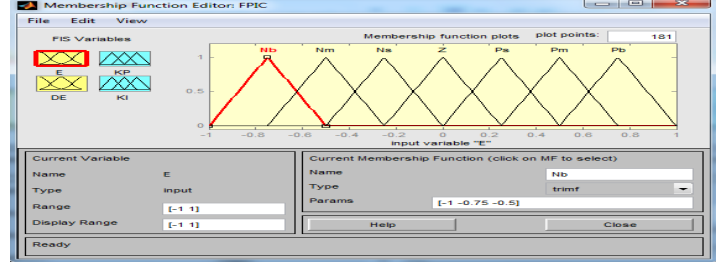

(b)

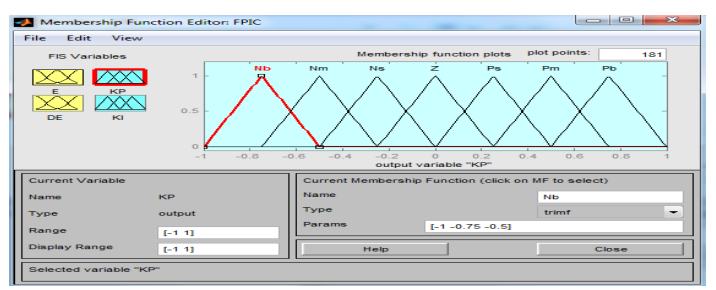

(d)

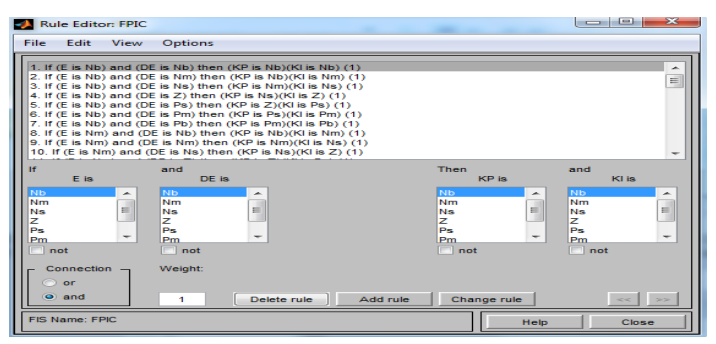

(f) 

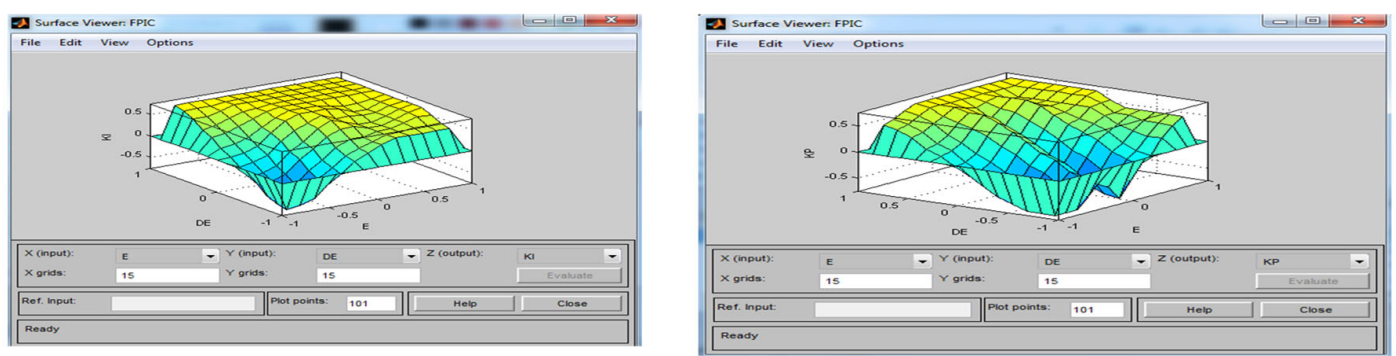

(g)

Figure 20. Simulation response of the system at variable load with FLPI controller, (a) FIS of FLPI, (b) membership function of (error), (c) Membership function of I/P (change of error), (d) Membership function of O/P (Kp), (e) Membership function of O/P (Ki), (f) Rules of FIPI, (g) Surface viewer of FIPI

The difference between the different simulations can observe by responding to each case and comparing it with the response of any other case that simulates the operation of the engine with different states. When looking at all cases in terms of response: close symmetry appears, and when looking at the response clearly. A slight difference can be observed. It is almost an override of $2 \mathrm{rad} / \mathrm{s}$, and then it can be said that a better response has obtained. A slight difference can observe by taking the time to reach the stable state and these are the system specifications to demonstrate the differences and to determine better performance. It includes Steady state error (ess), Peak Overshoot (Mp) and Settling Time (tss) that shows the better state by using fuzzy logic controller compared to conventional PID.

\section{CONCLUSION}

The main object of this paper is to implement a controller based on adaptive fuzzy-PI and conventional PI by using MathLab Simulink environment in order to improve the performance of three-phase induction motor under different operation conditions represent in (no-load, constant and variable loads), simulation results refer to successful techniques with high accuracy by using fuzzy-PI than conventional PI.

\section{REFERENCES}

[1] Mahdi Atig, Mustapha Bouheraoua, Arezki Fekik, "An Experimental Investigation of Heating in Induction Motor under Open Phase Fault," International Journal of Electrical and Computer Engineering (IJECE), vol. 8, no. 3, pp. 1288-1296, June 2018.

[2] Aderibigbe, Israel Adekitan, Adeyinka Adewale, and Alashiri Olaitan, "Determining the operational status of a Three Phase Induction Motor using a predictive data mining model," International Journal of Power Electronics and Drive Systems, vol. 10, no. 1, pp. 93-103, 2019.

[3] Farah, Nabil, et al., "Self-tuning Fuzzy Logic Controller Based on Takagi-Sugeno Applied to Induction Motor Drives," International Journal of Power Electronics and Drive Systems, vol. 9, no. 4, pp. 1967-1975, 2018.

[4] Abdullah, Afrah Thamer, and Amer Mejbel Ali, "Thermal analysis of a three-phase induction motor based on motor-CAD, flux2D, and matlab," Indonesian Journal of Electrical Engineering and Computer Science, vol. 15, no. 1 , pp. 46-53, 2019.

[5] Denai, Mouloud Azzedine, and Sid Ahmed Attia, "Fuzzy and neural control of an induction motor," Applied mathematics and computer science, vol. 12, no. 2, pp. 221-234, 2002.

[6] Ayushi, "Speed Control of Induction Motor using Fuzzy Logic Controller," International Journal of Advanced Research in Electrical, Electronic and Instrumentation Engineering, vol.4, no.4, pp. 2581-2588, Apr, 2015.

[7] M. Zerikat, and S. Chekroun, "Design and Implementation of a Hybrid Fuzzy Controller for a High-Performance Induction Motor," International Journal of Electrical, Computer Energetic, Electronic and Communication Engineering, vol.1, no. 2, pp. 202-208, 2007.

[8] Madhavi L. Mhaisgawali, Mrs.S.P. Muley, "Speed Control of Induction Motor using PI and PID Controller," IOSR Journal of Engineering (IOSRJEN), vol.3, no. 5, pp.25-30, May 2013.

[9] Mr. Bidwe Umesh. B., Mr. Shinde Sanjay. M., " Speed Control of Three Phase Induction Motor using Fuzzy- PID Controlller," International Journal of Engineering Research and Technology (IJERT), vol. 2, no. 11, pp. 3794 3799, Nov 2013.

[10] Kamini Devi, Shailendra Gautam, Deepak Nagaria, " Speed Control of 3-Phase Induction Motor Using Self-Tuning Fuzzy PID Controller and Conventional PID Controller," International Journal of Information and Computation Technology, vol. 4, no.12, pp.1185-1193, 2014.

Int J Pow Elec \& Dri Syst, Vol. 11, No. 2, June $2020: 762-773$ 
[11] Hesari, Sadegh, et al., "Investigating the Intelligent Methods of Loss Minimization in Induction Motors," TELKOMNIKA (Telecommunication, Computing, Electronics and Control), vol. 16, no.3, pp. 1034-1053, 2018.

[12] Salam Waley, Chengxiong Mao, "Artificial Optimal Fuzzy Control Strategy for Elevator Drive System by Using Permanent Magnet Synchronous Motor", Indonesian Journal of Electrical Engineering and Computer Science, vol. 14, no. 3, pp. 470-480, Jun 2015,

[13] Ahmed m. Kassem, "Fuzzy-Logic Based Self-Tuning PI Controller for High-Performance Vector Controlled Induction Motor Fed PV-Generator," WSEAS TRANSACTION on SYSTEMS, vol. 12, no. 1, Jan, 2013.

[14] Hanan Mikhael D. Habbi, Hussein Jalil Ajeel, Inaam Ibrahim Ali, "Speed Control of Induction Motor using PI and V/F Scalar Vector Controllers," International Journal of Computer Applications, vol. 151, no. 7, pp. 36-43, Oct 2016.

[15] Naveena G J, Murugesh Dodakundi, Anand Layadgundi, "Speed control of an induction motor using fuzzy logic and pi controller and comparison of controllers based on speed," International Journal of Electrical and Electronics Engineers, vol. 7, no. 1, 2015.

[16] Adnan Jabbar Attiya, Yang Wenyu1, Salam Waley Shneen, "Compared with PI, Fuzzy-PI and PSO-PI controllers of robotic grinding force servo system," Indonesian Journal of Electrical Engineering and Computer Science, vol. 16, no. 1, pp. 65-74, Oct 2015.

[17] Adnan Jabbar Attiya, et al, "PSO_PI Controller of Robotic Grinding Force Servo System," Indonesian Journal of Electrical Engineering and Computer Science vol. 15, no.3, pp. 515-525, Sep 2015.

[18] Bambang Purwahyudi, et al, "Self-Tuning Fuzzy-PI Controller in Volts/ Hz Induction Motor Control for Electrically Driven Ship Propeller," Academic Research International, vol. 5, no. 5, pp. 86-94, Sep 2014.

[19] Salam Waley Shneen, "Advanced optimal for three phase rectifiers in power electronics system," Indonesian Journal of Electrical Engineering and Computer Science, vol. 11, no. 3, pp.821-830, Sep 2018.

[20] Salam Waley, Chengxiong Mao, Nasseer K. Bachache, "Biogeography Based Optimization Tuned Fuzzy Logic Controller to Adjust Speed of Electric Vehicle," Indonesian Journal of Electrical Engineering and Computer Science, vol. 16, no. 3, pp. 509-519, Dec 2015.

[21] Adnan Jabbar Attiya, et al, "Fuzzy-PID controller of robotic grinding force servo system," Indonesian Journal of Electrical Engineering and Computer Science, vol. 15, no. 1, pp. 87-99, Jul 2015.

[22] Yakala Satyanarayana, Dr.A. Srujana, "Speed Control of Induction Motor using Fuzzy PI Controller based on Space Vector Pulse Width Modulation", International Journal of Computational Engineering Research, vol. 2, no. 5, pp. 1203-1209, Sep 2012.

[23] Ismail Khalil Bousserhane, Abdeldjebar Hazzab, Mostefa Rahli, Benyounes Mazari, Mokhtar Kamli, "Optimal fuzzy gains scheduling of PI controller for induction motor speed control," Faculty of Electrical Engineering and Informatics, Technical University of Kosice, Solvak Republic, vol. 7, No.1, 2007 